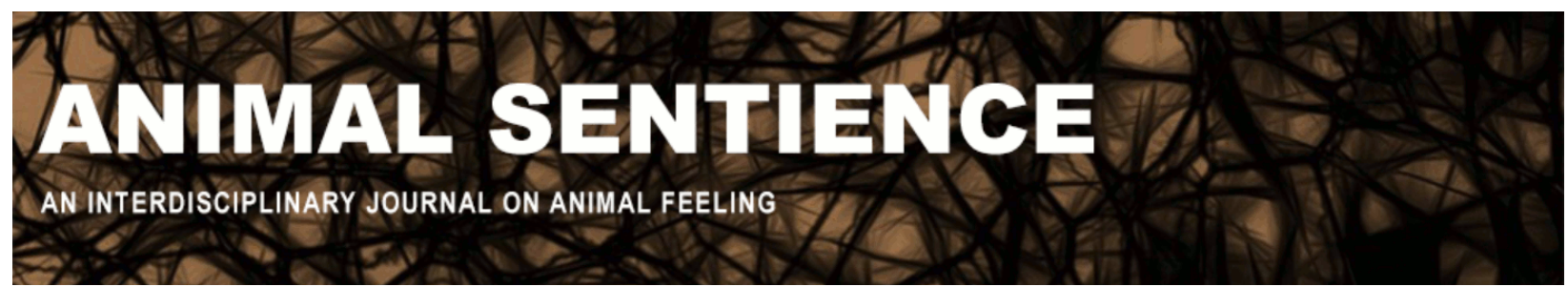

Stauffer, Jay R., Jr. (2017) The potential for sentience in fishes. Animal Sentience $8(4)$

DOI: $10.51291 / 2377-7478.1186$

Date of submission: 2017-01-06

Date of acceptance: 2017-02-02

(c) (†)

This article has appeared in the journal Animal

Sentience, a peer-reviewed journal on animal

cognition and feeling. It has been made open access,

free for all, by WellBeing International and deposited

in the WBI Studies Repository. For more information,

please contact

wbisr-info@wellbeingintl.org.

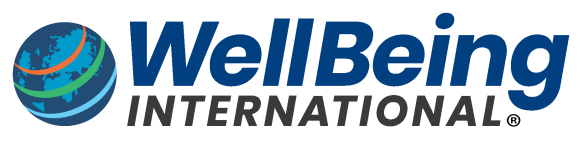

SOLUTIONS FOR PEOPLE, ANIMALS AND ENVIRONMENT 


\title{
The potential for sentience in fishes
}

\author{
Commentary on Balcombe on Fish Knows
}

\author{
Jay R. Stauffer, Jr. \\ Department of Ecosystem Science and Management \\ Penn State University
}

\begin{abstract}
Balcombe's book is filled with information on the biology, behavior, and life history of fishes. I do not agree with all his premises. I am still somewhat perplexed about the discussion of whether fish feel pain; I am not sure whether the distinction between nociception and pain makes any difference. Overall, however, his treatment of the principles of both natural and sexual selection is comprehensive and accurate, and has greatly increased my knowledge and awareness of the biology, ethology, and potential for sentience in fishes. In summary, this work has exposed me to new ideas about how to examine fishes and it has forced me to think about and explore many of the concepts presented.
\end{abstract}

Jay R. Stauffer, Jr. is Distinguished Professor of Ichthyology at Penn State University. His research is on endangered fishes, freshwater fish behavior, the impact of introduced fishes, and the systematics and zoogeography of freshwater fishes.

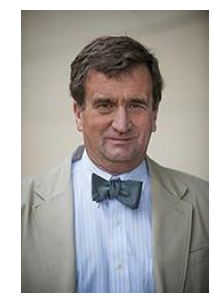
http://ecosystems.psu.edu/directory/vc5

I hesitated before I accepted the invitation to review this book (Balcombe 2016a, b). On the surface, I have perceptions fundamentally different from those of the author. I am a taxonomist who specializes in fishes. My museum holds over $1 \times 10^{6}$ fishes. I fish recreationally and I am an avid archery hunter, but more on that later.

After reading this book completely in three sittings, I am extremely impressed. Balcombe presents the material in a logical, concise manner. There are very few grammatical errors (e.g., ending sentences with prepositions) and for the most part, the major points are supported by references to the primary literature. There are some inconsistencies in the accuracy of the material presented. For example, a footnote on page 11 correctly notes that "Some scientists place the chimaeras ... in a separate group," but on page 12 he implies that birds and reptiles are in fact separate classes of vertebrates.

There are several places in the text where in my opinion, Balcombe is a tad too anthropomorphic. For example, he opines that the inability of certain flounders to effectively mimic their surroundings when their eye is not functional "... hints at some level of conscious control ..." when in fact it may be a feedback system involving nerve impulses between the eye and chromatophores (p. 26). Moreover, he suggests that because goldfish can be fooled by an optical illusion, that "... what goldfish brains are doing is the same as what ours do ..." (p. 37). In 
numerous places, he makes the assumption that the effect of chemicals in a fish has the same function as it does in humans (see discussion of cortisol and antidepressants pp. 92-94). Although his conclusions may be correct, one needs to be careful about these generalizations. For example, because we find lactase in fishes, it does not follow that they drink milk. To be fair, Balcombe cautions against anthropomorphisms (p. 48).

Additionally, there are some statements that, to me, push his goal to present the diversity, uniqueness, and sentience of fishes a bit far. For example, he suggests that "... fishes probably invented hearing ..." (p. 40), but we know that many invertebrates respond to vibrations and sounds. There are other generalizations that are taken out of context. He states "... as recently as the 1930s, scientists believed that fishes were deaf" (p. 41). That statement has no foundation and I could just as easily state that as of 2017 scientists denied evolution, even though the vast majority of biologists think that evolution is the unifying concept in all of biology.

Throughout the text, Balcombe underscores the basics of evolution. On occasion, in his efforts to "humanize" fishes there is a reversal of events. When discussing taste, he states that fishes need taste "... for the same reasons we do" (p. 54). Overall, however, his treatment of the principles of both natural and sexual selection is comprehensive, accurate, and accompanied by many important examples with the appropriate citations. The text is filled with a great deal of information on the biology, behavior, and life history of fishes.

I am somewhat perplexed about the discussion of whether fish feel pain. Balcombe distinguishes between an organism avoiding a negative stimulus as a result of an interaction of nerves and muscles that is independent of recognition of pain in the brain (i.e., nociception) and a conscious perception of pain. In terms of the benefits of recognizing pain, I am not sure if this distinction makes any difference. My puzzlement about this discussion most likely results from my lack of knowledge about the difference, rather than his discussion of it. I infer from his comments and many footnotes that he is suggesting that we refrain from commercially and recreationally harvesting fishes. His text has not convinced me to become a vegetarian, but that is my personal bias.

The discussion of the inherent problems of aquaculture, in particular cage culture, of fishes is excellent. Balcombe clearly presents the problems associated with increase in disease organisms, parasites, and eutrophication, which are associated with such farming. In his efforts to promote the responsible care of fishes, he applauds when test organisms are released back into their original capture sites. One should note, however, that in some instances, this practice can also introduce disease organisms into the wild. In several studies in which I have used capture fishes in laboratory-based behavioral or breeding experiments, the Pennsylvania Fish and Boat Commission (PFBC) prohibited the release of these organisms back into the wild for just those reasons. The PFBC was also concerned with the potential of the release of laboratorybred fishes, altering the gene pool of wild stocks.

As stated in the first paragraph, I collect fishes throughout North America, Nicaragua, and Malawi. In an effort to reduce discomfort (pain?), I anesthetize all specimens in clove oil before preservation. I am a firm believer in the necessity of natural history museums. I have used fishes that were preserved and catalogued into the museum at Penn State over 50 years ago to document the impact of various stresses. Without these collections, it would not have been possible to document the adverse impact on our aquatic resources. My students and I 
have also reconstructed macroinvertebrate communities by dissecting the stomachs of preserved fishes collected in the 1990s. At the same time, I recognize that some fishes are so rare that they should not be collected or preserved. I have pioneered the cataloging of digital photos and underwater videos into the Penn State Fish Museum, in order to document these communities and at the same time preserve a date- and time-stamped underwater image that can be used to verify their existence.

I have been studying fishes in museums and in situ since 1969. The reading of this text has greatly increased my knowledge and awareness of the biology, ethology, and potential for sentience in fishes. I have taught ichthyology for some 40 years, and I assure you that this book will appear on my reading list for both undergraduate and graduate students starting this year. I recommend this book to all of my colleagues. I admit that I do not agree with all the premises proposed in this text, but it has exposed me to new ideas about how to examine fishes and it has forced me to think about and explore many of the concepts presented - and is not this what science is all about? Congratulations to Jonathan Balcombe for an excellent work!

\section{References}

Balcombe, J. (2016a). What a Fish Knows: The Inner Lives of Our Underwater Cousins. New York: Scientific American/Farrar, Straus and Giroux.

Balcombe, J. (2016b). In praise of fishes: Précis of What a fish knows (Balcombe 2016). Animal Sentience, 8(1). 